\title{
Earth summit raises expectations
}

The UN Conference arranged for June is more likely to succeed if over-ambitious planning can be somehow tempered by a sense of what is politically and financially feasible.

THE United Nations, much strengthened in reputation by events of the past two years and, more recently, by the appointment of one good secretary-general to succeed another, should think hard about the conference on Environment and Development, otherwise the 'Earth Summit', to be held in Rio de Janeiro in June. There are two dangers. First, an agenda almost predestined to be overambitious is also predestined to disappoint the enthusiasts who will be watching what happens at Rio. Second, to the extent that one objective of the conference is to explore the needs of developing countries for the technical and financial assistance that will enable them to follow commonly determined environmental goals, the conflict (rather than the identity) of interests between developing and developed countries may be rancorously re-advertised. It is in everybody's interest that ambitions for Rio should be curtailed.

The central disagreement about the likely agenda for Rio (being drafted in New York this week and during the next four) is that embodied in the saying that "the best is often the enemy of the good", which means that the pursuit of an ideal may impede, even prevent, the attainment of lesser but worthwhile goals. At one extreme, in the interests of what Adlai Stevenson once called "the care and maintenance of a small planet", there is a plan for asking the governments participating at Rio to sign a declaration tantamount to a recipe for the long-term preservation of the surface of the Earth much as it is now, together with an acknowledgement of the financial obligations to developing countries implied by consequential restraints on development. At the other is the view that Rio should be an occasion for settling a few urgent matters, among which the most urgent is a convention to safeguard against the threat of global climatic change. It will be the better if the second wins support.

The case for a convention on greenhouse gases is urgent because the prospect of global warming caused by the accumulation of carbon dioxide, while not proved to the hilt, is substantial and immediate on the timescale of diplomatic negotiations on such contentious issues. Many other matters being canvassed for Rio as issues in their own right, deforestation for example, are parts of that problem, but should strictly be compared with other contributory causes (the continuing use of chlorofluorocarbons, which are also greenhouse gases) and partial remedies (such as nuclear power). But the comparison is far from simple. Nobody could now seriously pretend that a greenhouse convention accurately trading off one kind of emission against another could be signed at Rio. The best hope is that participating governments will agree that there is a problem to be solved, and will then establish a mechanism to that end. The worst is that there will be an agreement implying the uneconomic use of resources - and from which many important governments will stand aside.

Sadly, there seems an ambition among the organizers to make Rio an occasion when black sheep will be recognized (and pilloried) as such. The United States, consistently sceptical of global warming, is the most conspicuous. But what purpose would be served if the expected wrangle over a greenhouse convention served further to isolate the government which at present spends most on relevant research, and whose own practices are one of the principal contributors to atmospheric carbon dioxide. (Canada, per capita, is marginally more prolific a source.)

More generally, the preparations for Rio seem to imply that, if only recalcitrant politicians would agree, the world's environmental problems could be settled at Rio once and for all. There may, of course, be value in another comprehensive statement of what these problems are, but who can seriously pretend that enough is yet known of them for remedies to be designed in the next few months? The best course for the time being would be to use this global statement as a means of winning agreement that there needs to be a better mechanism for winning collaboration between governments of problems other than global warming that are certain to arise in the future. Just that, of course, would disappoint the enthusiasts, but if they win more, it will be the worse for the rest of us.

\section{US biotechnology policy}

Products pose no special risks just because of the processes used to make them

THE Administration of US President George Bush has just issued a policy on the regulation of biotechnology that is utterly in keeping with good science. Perhaps it should not be surprising that this is so, but for the past two decades biotechnology has gained such a reputation as a bogeyman of science that it is refreshing to see that clear 